\title{
Modifications of a spark ignition engine to operate with hydrogen and methane blends
}

\author{
F. Moreno ${ }^{1}$, M. Muñoz, O. Magén, C. Monné, J. Arroyo \\ ${ }^{1}$ Laboratorio de Motores, Department of Mechanical Engineering \\ C.P.S., University of Zaragoza \\ Edificio Torres Quevedo - C / María de Luna s/n, 50018- Zaragoza (Spain) \\ Phone/Fax number: 0034976762 552, e-mail: fmoreno@unizar.es
}

\begin{abstract}
An investigation project is carrying out with the aim to analyze deeply the performance of spark ignition engines fuelled with hydrogen and methane blends in the widest range of operation conditions. This project comprises two phases. This paper is focused to the first one, which expose the selection of engines to achieve the aim of the investigation project, the modifications and sensorization that engines require for hydrogen and methane blends and testing and the gaseous fuel supply line implemented in the testing bench under the most strict safety and efficiency conditions according to technical specifications of installations and equipment for hydrogen.
\end{abstract}

\section{Key words}

Hydrogen and methane blends, Spark ignition engine, NOx emissions, Lean operation conditions, Thermal dilution.

\section{Introduction}

While hydrogen fuel cells achieve enough maturity, hydrogen could be used in internal combustion engines to contribute to a smooth transition to the hydrogen economy which is approaching as an energetic alternative economy. Good hydrogen properties and easy modifications of the machinery with low costs permit to convert an Internal Combustion (IC) engine in hydrogen fuelled engine. This strategy may play a relevant role in this energetic economy transition. On the other hand, the properties of hydrogen used as fuel generates some performance problems in internal combustion engines, as the backfire, the knock and NOx emissions, which can be controlled by new management strategies of the engine. Thermal dilution systems as Exhaust Gas Recirculation (EGR) and Water Injection System (WIS) amongst others have to be implemented in engines. The management of these systems permits to develop strategies to minimize the problems that hydrogen properties present.

To understand strictly main aspects of performance of IC engines fuelled with hydrogen, firstly it's basic to analyze the physicochemical properties of this fuel. Some of them determine the advantages of hydrogen as fuel in IC engines.

For example, the hydrogen shows a wide flammability range. This property provides a complete combustion under lean operation conditions, besides allowing the engine operates in low load conditions even with Wide Open Throttle (WOT) [1]. The autoignition temperature of hydrogen is higher than gasoline. That involves higher compression ratio could be used in IC engines fuelled with hydrogen. Moreover this effect improves the indicated thermal efficiency of IC engines. Therefore, the improvements of performance in IC engines using hydrogen as fuel are better in Spark Ignition (SI) engines than in Compression Ignition (CI) Engines. For this reason, the project that focuses this paper deals specifically with SI engines the use of hydrogen and methane blends. On the other hand, while hydrogen combustion process occurs, the flame propagation is carried out a very high velocity. This effect approaches the real process to ideal process (heat released at constant volume) which provides the maximal indicated thermal efficiency [1]. Likewise, the high diffusion coefficient of hydrogen involves a very quick and a homogenous airfuel mixture.

However, hydrogen used as fuel in SI engines generates significant problems. Main problems are the backfire, rise of knock and NOx emissions [2]-[4], which are detailed as follows. There are several reasons which cause the backfire as preignition sources in hot points as spark plugs or residual gases [2], induction generated between wires in ignition system [5]-[7], flame remains into piston crevices [5],[8] and so on. Due to that, many solutions could be taken: cold spark plugs, stand alone ignition, thermal dilution systems as EGR and WIS, etc. [2],[6]. In order to knock problems, air-fuel ratio and compression ratio have a lot of influence on this effect. It has to find a balance between both parameters to reduce this effect as much as possible. On this way, lean operating conditions and retarding the ignition timing might be a solution of the knock effect [1],[9]. On the 
other hand, the hydrogen combustion process produces NOx as result of dissociation of nitrogen included in the air. This phenomenon occurs in high temperature regions [10]. Nevertheless, hydrogen permits complete combustion process under very lean operation conditions. This property involves a significant reduction of the combustion temperature and in consequence the NOx production [1]. In addition, reducing the ignition timing and installing thermal dilution systems, as EGR and WIS, contribute to reduce the NOx production [10],[11].

Another very interesting possibility in a SI engine is the use of hydrogen as additive of gasoline or blended with methane or natural gas, which is formed primarily of methane. In the first option, the hydrogen is used as fuel in idle and low load operation conditions. As it was indicated above, the properties of hydrogen allows the performance of engine in these operation conditions even with WOT. When the mixture requirements of a SI engine rise, the percentage of gasoline is increased progressively. This strategy allows reducing the lean operation limit of gasoline, the time of combustion and the cyclical variability that every IC engine shows typically. At the same time, the efficiency is rising and the power is reducing [12]. The second option is the use of hydrogen blended with natural gas or methane as fuel. This option is the base of the investigation project which is the main focus of this paper. For this reason, the use of hydrogen blended with natural gas or methane as fuel is explained deeply in the following section.

\section{Interest of hydrogen and methane blends}

The use of natural gas as fuel in SI engines presents several positive aspects. The natural gas as fuel provides high indicated thermal efficiency, low knock probability and reduced NOx emissions. However, some problems occur, as low flame velocity and rise of cyclical variability. One way to avoid these problems is the addiction of hydrogen to natural gas [13]. Moderated concentrations of hydrogen don't affect excellent knock resistance properties of natural gas. Nevertheless, when the hydrogen ratio increases, the knock effect is shown earlier. On the other hand, the indicated thermal efficiency is increased if the ratio of hydrogen increases [13]-[15], mainly under lean operation conditions and ignition timing lightly retarded regarding the optimal. The maximum indicated thermal efficiency and maximum power are achieved with blends which contain around $20 \%-25 \%$ of hydrogen in volume [14] and the knock effect still doesn't appear. According to other investigations, the optimal ratio of hydrogen to obtain the maximum indicated thermal efficiency is even higher (30\% [16] or $50 \%$ [17]) the minimal fuel consumption is achieved of a ratio of hydrogen of $60 \%$ [15]. The cyclical variability is as well reduced increasing the ratio of hydrogen. This influence is more important under lean operation conditions and ignition timing lightly retarded regarding the optimal.

Under an environmental point of view, a hydrogen and methane blends reduce $\mathrm{CO}, \mathrm{CO} 2 \mathrm{CH} 4$ emissions due to the content of carbon is smaller compared to gasoline.
However, NOx emissions increase with ratio of hydrogen [13],[15],[17]. Hydrogen ratios between 28\%-36\% and fuel-air equivalence ratio of 0,6 reduce NOx emissions up to extremely low levels. Under these operation conditions, the unburned hydrocarbon level is acceptable. According to these experiences, blends of $20 \%$ of hydrogen don't provide enough reduction of NOx emissions as to be the only solution. An effective strategy to reduce NOx in SI engines fuelled with hydrogen and methane blends is the use of EGR systems [18]. Although hydrocarbons and $\mathrm{CO} 2$ emissions increase with EGR ratio and $\mathrm{CO}$ emissions hardly are modified, the indicated thermal efficiency is as well increased with EGR system. The optimal ratio of exhaust gas recirculation might be around $13 \%$ and $15 \%$ with a hydrogen ratio between $15 \%$ and $20 \%$ respectively. [18].

In conclusion, the use of hydrogen in IC engines well as pure fuel, good like additive of natural gas, gasoline, etc, provides indisputable advantages at the same time that some significant problems. Therefore, this is a field which has to be research in depth. On this way it will be possible to find out the operation limits of this fuel and the modifications to carry out in internal combustion engines to keep a reasonable performance and low pollutant emissions.

To contribute to research in this field, the Department of Mechanical Engineering of the Zaragoza University is carrying out an investigation project with the aim to analyze deeply the performance of every kind of spark ignition engines fuelled by hydrogen and hydrogen and methane blends in the widest range of operation conditions. On this way, several strict tests will be carried out in a high accuracy testing bench placed in the Laboratorio de Motores of the Department of Mechanical Engineering next to a deep extension of testing bench to include a gaseous fuel supply line.

This investigation project comprises two main phases. The first one starts with the selection of engines. Commercial engines that main manufacturers provide are deeply analyzed to select the models which technical specifications better achieve the aim of the investigation project. After engines are selected, every modification necessary to operate with hydrogen and hydrogen and methane blends have been carefully carried out in engines. Likewise, engines have to be correctly sensorized to for data acquisition in testing bench during the tests. On the other hand, the use of new gaseous fuels in engines requires a new gaseous fuel supply totally safe and efficient. In order to that, a new gaseous fuel supply line has to be implemented in the testing bench under these conditions (safety and efficiency). Notice that all modifications and new systems installed as in engines as in the testing bench has been carried out according to technical specifications of installations and equipment for hydrogen, due to these are the strictest gaseous requirements. Like that, the testing bench is able to test engines fuelled with every kind of gaseous fuel.

The second phase of the investigation project is dedicated to specific and strict tests as using pure hydrogen as using 
any hydrogen and methane blend carried out in the testing bench extended for gaseous fuel supply with the engines previously selected and modified in the first phase. The main objective of every test is to analyze deeply the performance of engines and to obtain the complete characterization of the engine for every possible gaseous fuel blend, from pure methane to pure hydrogen, as well hydrogen blended with other gaseous or liquid fuels. As result of the tests, the high accurate equipment belong to testing bench permits to acquire detailed measures of power, torque, fuel consumption, air fuel ratio, indicated diagram, pollutant emissions, EGR flow influence, water ignition flow influence, optimal ignition requirements, optimal fuel ignition requirements.

Currently the first phase of the project is finishing. Therefore, the modifications of engines and testing bench under hydrogen requirements are in process. This process of modifications requires depth knowledge's of engines, accurate instrumentation, fuels, gas supply installations, gas safety systems and so on. As well an accurate and complex experimental development is necessary to carry out the implementation of all new systems and modifications required to convert a commercial gasoline engine in an experimental gaseous engine and to extend a testing bench able for liquid fuel to a testing bench for liquid and gaseous fuels totally safe and efficient. All this accurate implementation makes up the base to carry out the strict tests. Therefore, this paper is focused to expose the first phase of this project: selection of engines, a detailed way of the procedure of adaptation of engines and adaptation of testing bench to operate with pure hydrogen and hydrogen and methane blends.

\section{Experimental installations}

As a first step to start this project, a commercial four stroke engine fuelled by gasoline was selected. This kind of engines has good qualities to be modified relatively easy to operate with gaseous fuels and carry out normalized test in an engine testing bench. The detailed engine specifications are shown in Table 1.

Table 1. Specifications of selected engine

\begin{tabular}{|l|c|}
\hline Engine Brand/Model & Lombardini / LGW 523 MPI \\
\hline Engine cycle & 4-stroke OTTO cycle \\
\hline Cooling system & Water cooled \\
\hline Number of cylinders & 2 in line \\
\hline Displacement & $505 \mathrm{~cm} 3$ \\
\hline Bore & $72 \mathrm{~mm}$ \\
\hline Stroke & $62 \mathrm{~mm}$ \\
\hline Compression ratio & $10,7: 1$ \\
\hline Valves per cylinder & 2 \\
\hline Injection and ignition system & $\begin{array}{r}\text { Electronic indirect fuel } \\
\text { injection. Waste-spark } \\
\text { electronic ignition system. }\end{array}$ \\
\hline
\end{tabular}

As it was indicated before, the main problems generated when hydrogen is used as fuel in a SIE are the backfire, the knock and NOx emissions. For this reason, to characterize in depth the engine it must install appropriate instrumentation equipment into the engine (Fig. 1), also introduce new systems and make changes in some components (new gaseous fuel system, thermal dilution systems, ignition system modifications, etc). On the other hand, it has to develop new ignition and injection strategies as well as find out suitable strategies of Water Injection and EGR.

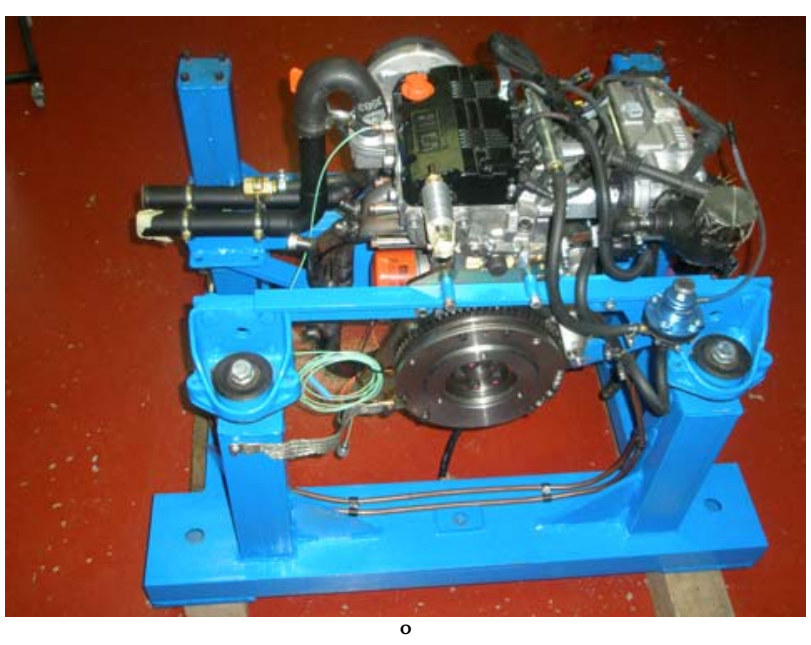

Fig. 1. Two general views of engine modified.

According to that, notice that the original manifold has had to be modified to install the gaseous injectors keeping at the same time the original gasoline injectors. (Fig. 2) In order to that, a new component called "secondary manifold" has been designed, built and assembled.

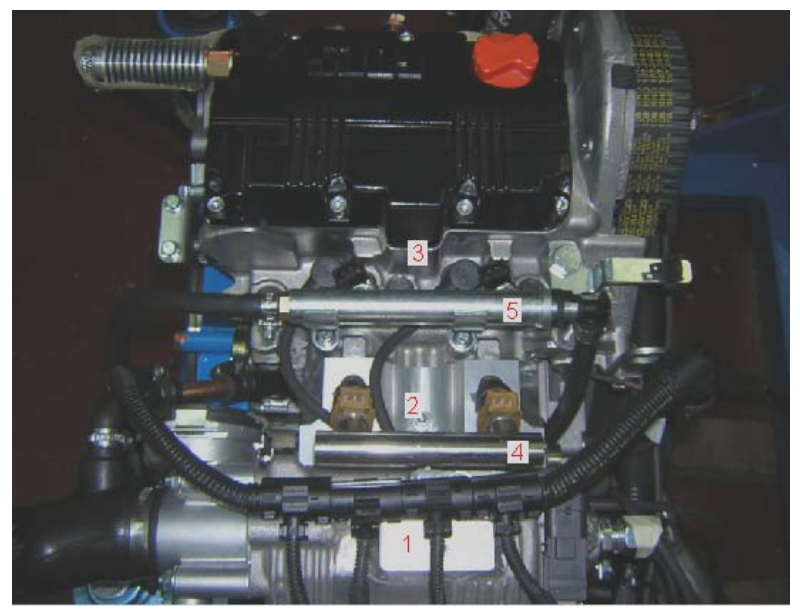

Fig. 2. Some modifications made in the inlet manifold. (1-Air inlet manifold; 2-Secondary manifold; 3-Cylinder head; 4-

Gaseous fuel injection system; 5-Gasoline fuel injection system)

Likewise, the engine has been equipped with a stand alone ignition system in order to minimize the backfire effect by hot points into the combustion chamber or induction generated in ignition system. Two BERU coils and two NGK spark plugs with a thermal grade colder than the original ones have been installed in the engine. 
To research with water injection strategies to reduce the NOx production an AEM 30-3002 Universal Water/Methanol Injection kit has been assembled in the air intake manifold. Like that thermal dilution is achieved by water injection simultaneously with fuel injection into the combustion chamber. Another thermal dilution system realized is the exhaust gas recirculation system by an electronic EGR valve obtained from an Opel 1.6 engine.

The original Electronic Control Unit (ECU) of the engine is totally locked, as usual in commercial engines. It involves that neither to modify any original setting nor to manage any new system to the engine it's possible from the original ECU. For this reason, the original ECU has been replaced for a Universal Programmable Engine Management System (PEMS). The model selected is the AEM 30-1900U Universal Programmable Engine Management System. In this manner, fuel injection, ignition, WIS and EGR go to be managed by the PEMS.

The new PEMS requires different sensors to determine the suitable operation conditions of the engine. Some of them was assembled into the original engine (rpm sensor, manifold temperature and pressure, coolant temperature, throttle position), but some other have to be installed specifically. These are indicated below:

- $\quad$ Cam sensor. This sensor is essential to carry out a sequential injection.

- Knock sensor. It detects the knock effect and permits to ECU to correct some program parameters.

- Wide band Universal Exhaust Gas Oxygen sensor (BOSCH LSU 4.2). It allows to show the exact fuel-air equivalence ratio which the engine is operating with.

The use of the PEMS selected, totally programmable and able to manage all engine systems, permits to develop all kind of strategies based on thermal dilution (WIS or EGR), ignition retarded, lean mixture, etc, to find out the best performance, thermal efficiency, low emissions, depending on the hydrogen and methane blend tested.

To deepen on performance of the engine and carry out advanced thermodynamic studies, a piezoelectric pressure sensor (Kistler 6053 CC60) has been installed in the combustion chamber (Fig. 3).

Finally, it has to emphasize that measuring of pollutant emissions goes to be carried out to complete the characterization of the engine. For this process, the testing bench disposes of gas analyzers of Signal brand [19]:

Carbon monoxide and carbon dioxide with infrared absorption analyzer (NDIR).

- Hydrocarbons with Flame Ionization Detector (FID) analyzer.

- NOx concentration with Chemiluminiscent analyzer.

- $\quad \mathrm{O}_{2}$ concentration with Parametric Analyzer

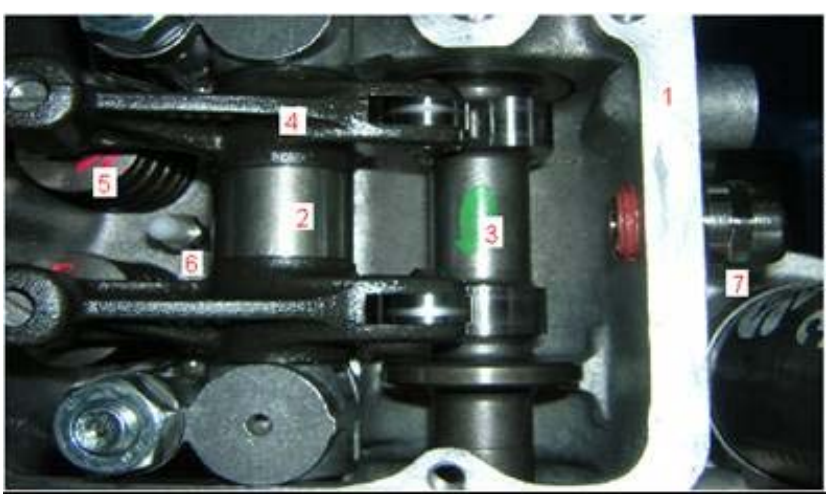

Fig. 3. Installation of cylinder head pressure sensor. (1-Cylinder head; 2-Rocker-arm shaft; 3-Camshaft; 4-Rocker arm; 5-Valve; 6-Combustion chamber pressure sensor; 7-Bulkhead)

On other matters, it is worth indicating that it has been to carry out some modifications in the testing bench to assure the correct gaseous fuel supply to the engine. For that, an additional gaseous fuel supply system has been designed. Nowadays this system is in a building phase. This system integrates the supply of methane-hydrogen blends but also the fuel measuring, control and safety systems that this kind of installation requires. Fig. 4 shows a basic scheme of system designed to supply the fuel to the engine.

The fuel supply system includes three sub-systems, which are exposed as follow. The first one is the fuel supply line, sensorized mainly by a two mass flow meter (MFM) calibrated for different range flow, MFM1 for low flow, MFM2 for high flow. Depending of fuel flow level, the measured realized will be MFM1 or MFM2. Fuel is supplied by two solenoid valves (SV), SV1 which is controlled by a safety system if some problem occurs, and SV3 which open the fuel supply to the fuel rail of engine. The MFM's are managed by its own software supplied by manufacturer.

The second sub-system tries to control the pressure in fuel rail and in manifold air intake. Fuel supply systems in a SI engine fuelled by injection try to keep as constant as possible the differential pressure between rail fuel and manifold air intake. This way assures a perfect control of fuel consumption by pulse width of injectors. Pneumatic differential pressure regulators can be found to carry out this purpose in injection engines fuelled by traditional fuels as gasoline, compressed natural gas, etc. But nowadays, there is not any manufacturer that supplies standard pneumatic differential pressure regulators for hydrogen. As well, the PEMS selected provides several correct curves to compensate the vacuum pressure in manifold air intake, load, throttle position, and so on. For this reason, we have decided to measure separately both pressures. To measure the pressure in fuel rail, the pressure regulator (PR3) fix the gauge pressure in the fuel rail and a fuel pressure transducer FPS send the pressure signal to PEMS. For the pressure in manifold air 
intake MPS send the pressure signal to PEMS, which calculates the correction depending on both signals received and adjusts the pulse width of injectors.

The third sub-system is the safety system. This system includes hydrocarbon catalytic sensors. If any leakage of hydrogen methane or any other flammable gases is detected by sensors, every SV shuts down. Also every fuel is shut down if any abnormal event is detected in testing bench or in engine. A second level force to SV2, SV3 and SV4 open to vent the line with nitrogen if the sensors detects gases level in the atmosphere is increasing. The safety system is managed by a logical system. Every risk conditions have to be realized and the orders to switch the different SV of system have to be programmed. Every SV are selected "normally closed" (NC). This is a safety measure which involves that if the electrical supply shut down, every SV closes and line remains locked.

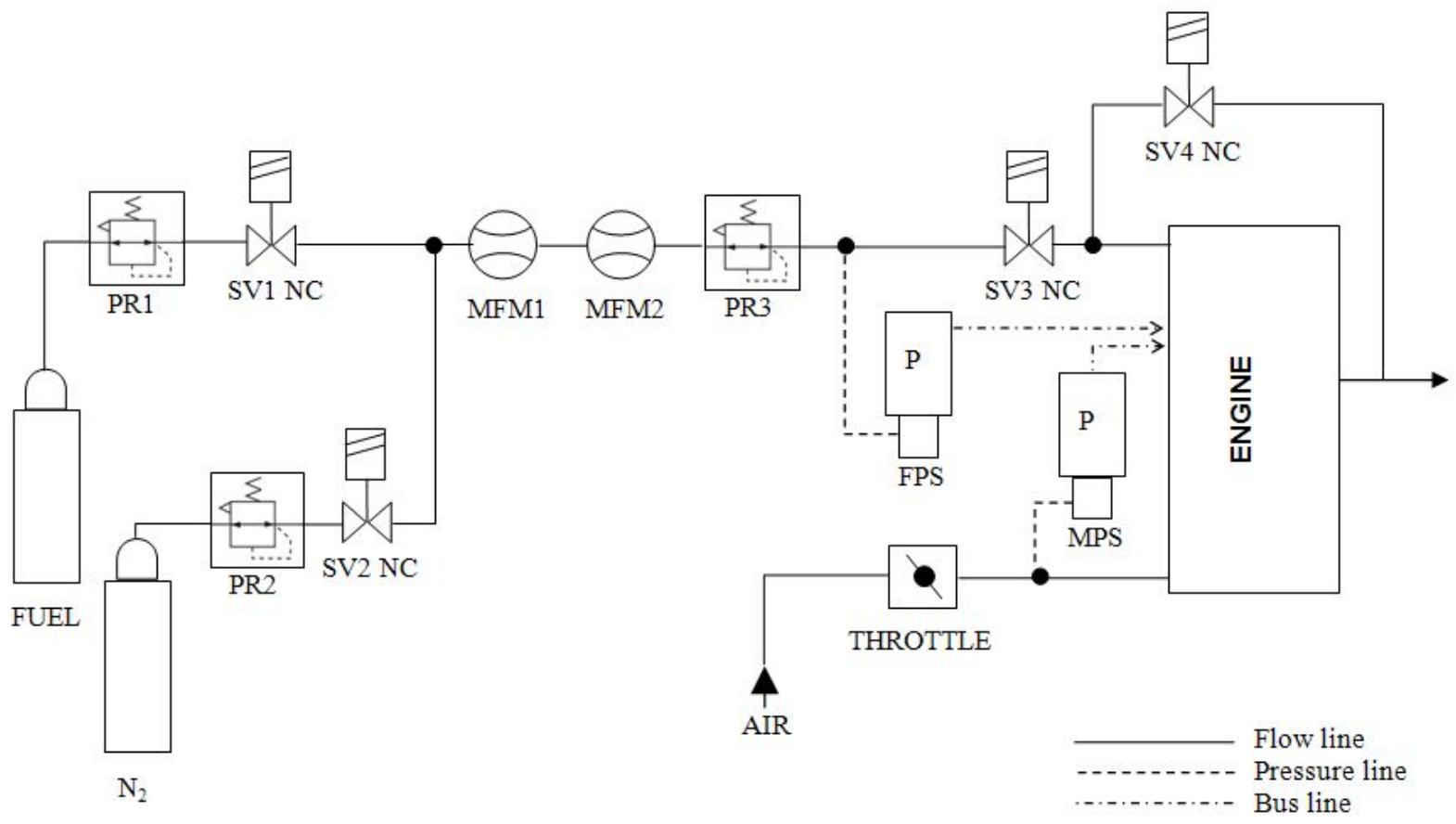

Fig. 4. Scheme of fuel supply installation. It includes the N2 vent system

\section{Conclusion}

The use of hydrogen in SI engines well as pure fuel, good like additive of natural gas, gasoline, etc, provides indisputable advantages at the same time that some significant problems. Therefore, that's a matter which has to be research in depth. On this way it will be possible to find out the operation limits of this fuel and the arrangements to carry out in internal combustion engines to keep a reasonable performance and low pollutant emissions. At the moment the investigation project disposes of an original SI engine fuelled by gasoline totally modified to operate with hydrogen-methane blends as fuel and it's possible to measure the basic performance as well as other interesting characteristics as indicated diagram, pollutant emissions, new ignition programs, EGR flow, etc. On the other hand, a gaseous fuel supply system, which includes measuring, control and safety systems, has been designed. Nowadays, this fuel supply system is in a building phase. When it was finished, the engine tests may be starting to carry out in the testing bench.

\section{Acknowledgement}

This investigation project is financed by the Ministry of Science and Innovation of Spain (ENE2008-06516-C0302) and co-financed by the FEDER program.

\section{References}

[1] White C.M., Steeper R.R., Lutz A.E. "The hydrogenfuelled internal combustion engine: a technical review". International Journal of Hydrogen Energy 31 (2006) 1292 $-1305$

[2] Verhelst S., Sierens R., Verstraeten S. "A critical review of experimental research on hydrogen fueled SI engines". Society of Automotive Engineers 2006-01-0430

[3] Szwaja S., Bhandary K.R., Naber J.D. "Comparisons of hydrogen and gasoline combustion knock in a spark ignition engine”. International Journal of Hydrogen Energy 32 (2007) 5076 - 5087

[4] Maher A.R. Sadiq Al-Baghdadi. "Effect of compression ratio, equivalence ratio and engine speed on the performance and emission characteristics of a spark ignition engine using hydrogen as a fuel”. Technical note, Renewable Energy 29 (2004) 2245-2260

[5] Lucas, G. G. and Morris, L. E. "The backfire problem of the hydrogen engine". Symposium organized by the 
university's internal combustion engine group, King's College, London, UK, 1980

[6] Kondo, T., Iio, S. and Hiruma, M. "A study on the mechanism of backfire in external mixture formation hydrogen engines - about backfire ocurred by the cause of the spark plug”. SAE, Paper No. 971704, 1997.

[7] MacCarley, C. A. "A study of factors influencing thermally induced backfiring in hydrogen fuelled engines, and methods for backfire control". 16th IECEC conference, Atlanta, USA, 1981

[8] Lee J. T., Kim Y.Y., Lee C.W.. "An investigation of a cause of backfire and its control due to crevice volumes in a hydrogen fuelled engine". Transactions of the ASME, Vol.123, January 2001, 204-210.

[9] Hailin L., Ghazi A. "Knock in spark ignition hydrogen engines”. International Journal of Hydrogen Energy 29 (2004) 859 - 865

[10] Subramanian V., Mallikarjuna J.M., Ramesh A. "Intake charge dilution effects on control of nitric oxide emission in a hydrogen fueled SI engine". International Journal of Hydrogen Energy 32 (2007) 2043 - 2056

[11] Subramanian V., Mallikarjuna J.M., Ramesh “A. Effect of water injection and spark timing on the nitric oxide emission and combustion parameters of a hydrogen fuelled spark ignition Enghien”. International Journal of Hydrogen Energy 32 (2007) 1159 - 1173

[12] D’Andrea T., Henshaw P.F., Ting D.S.-K. “The addition of hydrogen to a gasoline-fuelled SI engine”. International Journal of Hydrogen Energy 29 (2004) 1541 - 1552

[13] Karim G. A., Wierzba I. and Al-Alousi Y. "Methanehydrogen mixtures as fuels". International Journal of Hydrogen Energy Vol. 21, No. 7, pp. 625- 631. 1996

[14] Bade Shrestha S. O., Karim G. A. "Hydrogen as an additive to methane for spark ignition engine applications”. International Journal of Hydrogen Energy 24 (1999) 577-586

[15] Bauer C. G., Forest T. W. "Effect of hydrogen addition on the performance of methane-fueled vehicles. Part I: effect on S.I. engine performance". International Journal of Hydrogen Energy 26 (2001) 55-70

[16] Kahraman N, et al. "Investigation of combustion characteristics and emissions in a spark ignition engine fuelled with natural gas-hydrogen blends". International Journal of Hydrogen Energy (2008), doi:10.1016 /j.ijhydene.2008.10.075

[17] Fanhua M., Yu W., Haiquan L., Yong L., Junjun W., Shuli Z. "Experimental study on thermal efficiency and emission characteristics of a lean burn hydrogen enriched natural gas engine”. International Journal of Hydrogen Energy 32 (2007) 5067 - 5075

[18] Erjiang H., Zuohua H., Bing L., Jianjun Z., Xiaolei G., Bin H. "Experimental investigation on performance and emissions of a spark-ignition engine fuelled with natural gas-hydrogen blends combined with EGR”. International Journal of Hydrogen Energy 33 (2009) 528 - 539

[19] Moreno, F., Muñoz, M., Morea-Roy, J. "Sunflower methyl ester as a fuel for automobile diesel engines". 1999 American Society of Agricultural Engineers 0001-2351 / 99 / 4205-1181 Vol. 42(5): 1181-1185 